\title{
LATENT STRUCTURE OF SITUATIONAL EFFICIENCY PARAMETERS AT CROATIAN TOP BASKETBALL PLAYERS
}

\author{
Joško Sindik ${ }^{1}$, Igor Jukić ${ }^{2}$ and Maja Adžija ${ }^{3}$ \\ ${ }^{1}$ Institute for anthropological research, Zagreb, Croatia \\ ${ }^{2}$ Faculty of kinesiology, University of Zagreb, Croatia \\ ${ }^{3}$ International relations office, University of Zagreb, Croatia
}

\section{SUMMARY}

The aim of this study was to determine the structure of dimensions that are based on different parameters of the standard situational efficiency of top Croatian players. The insight into the structure and relationships of the latent dimensions of situational success in basketball could contribute to better understand the overall effectiveness of situational players. We analyzed twelve standard and seven derived parameters of situational efficiency in a intentional sample of players in nine senior basketball teams from the A-1 Croatian Basketball League Championship in 2006/2007. Principal components analysis of the standard situational efficiency parameters obtained the existence of three main components, which all together explain over $76 \%$ of the total variance of the space of standard parameters of situational efficiency. Univariate correlations and results of principal components analysis showed that the most standard and most of the derived parameters of situational efficiency are statistically significantly correlated.

Key Words: basketball, component analysis, correlation, latent dimensions.

\section{INTRODUCTION}

Basketball is a complex, variable poly-structural activity, characterized by cyclic and acyclic types of motions that precede primary goal of the game, basketball shooting, as well as preventing an opponent to win, and to make a shot. The basketball game in its course is divided into three main phases: defense, attack and transition (Jukić, 1998), and can be observed as a series of activities and tasks performed by each player regarding the place and role within a team concept game (Trninić, Perica, \& Dizdar, 1999). Basketball is a sport with contradictory tactics model of the game with infinite number of options to address specific situations in the game, while at the team level it is required opposition cooperation model (Hernandez, 1988). Therefore, the adjustment of individual and team goals, i.e. individual and team decisions is extremely important (Gréhaigne, Bouthier, \& Godbout, 1997; Trninić et al., 1999; Trninić \& Dizdar, 2000). The fundamental precondition for the successful operation of the individual in terms of performing the above series of operations is a set of selected features of the anthropological status, linked to an integrated set of optimal sports fitness. Characteristics that determine success in basketball are defined by the specification equation, which determines the optimal "sum" of characteristics that are the correlates of maximum sports performance (Milanović, Jukić, \& Dizdar, 1996). Monitoring and analysis of the situational efficiacy of the players and teams in basketball games contribute to easier monitoring of the spectators, and coaches and basketball professionals find them useful as a material that enables a comparative analysis of the players and teams as a whole and have their place in the planning and programming training process, indicates Maršić (Nakić, 2004). In order to monitor events at the basketball games FIBA (Federation International Basketball Association) has standardized thirteen situational efficacy indicators that are monitored at every official match. On that basis, it is possible to calculate 
various derived parameters. There have been conducted numerous scientific studies about the measuring problems of the actual quality of basketball players (Dežman, 1996; Dizdar, 2002; Elbel \& Allen, 1941; Erčulj, 1995; Swalgin, 1994, 1998). These studies were mainly focused on the development of expert systems to evaluate the actual quality of basketball players (Swalgin, 1994, 1998; Trninić et al., 1999). Dizdar (2002) has classified two basic methods for overall performance evaluation or actual quality of the players. The first method is a set of procedures for objective evaluation of the situational efficacy of the players, such as: a simple linear combination, a simple linear combination of $z$-values, partially pondered linear combination of the index of absolute and relative efficacy of the basketball players, MVP (most valuable player)-evaluation of the player's efficacy, Swalgin's $(1994,1998)$ systems for players evaluation (BES BES 1 and 2), the PC system for evaluating the performance of basketball players. The second group of methods includes the procedures for the subjective evaluation of the situational efficacy of the players, consisting of a group of independent basketball experts that evaluate certain group of basketball players according to one or more criteria. Although, of all the methods cited the "PC system for evaluating the performance of basketball players" proven to be most effective, equally efficient is the method of partly pondered linear combination (Dizdar, 2002), which uses the coefficients of shot efficacy rather than mere statistical data on the number of points scored and the number of unsuccessful shots.

In the context of this research, we review studies of authors who have studied the standard indicators of situational efficacy of the players. Trninić, Perica, and Dizdar (2001) gave a list of criteria for the situational evaluation of elite basketball players' efficacy in attack and defence, finding seven criteria for evaluating players in the set and the transition phase of defence, and twelve criteria of stage attacks. Milanović, Jukić, and Bračić (2001) found how much the variables of basketball shooting affected the results of the European Championship in Barcelona in 1997, and came to the conclusion that from the seven variables, only three appear as significant predictors of the final results of the match, while the most important one is the number of successful free throws. The other two significant variables were unsuccessful shots for two and three points. Abrams, Barnes, and Clement (2008) tried to determine the relationship between the statistical parameters that players had prior to the championship in the NBA league (Nati- onal Basketball Association) and the duration of sports career in the NBA (number of played seasons). The sample of the participants included consisted of guards, power forwards and centers. It has been analyzed eleven standard parameters of situational efficacy, and it turned out that there is a significant possibility of duration of the career forecasts based on these parameters, but only for basketball players at the position of guards and power forwards (not for the centers). For the players of American universities, Swalgin (1994) has established standards for evaluation for the efficacy of situational players by position in the game and playing time. He designed a computer program to evaluate the efficacy of basketball players, in relation to the position at which he plays and his presence in the game. In other sports games, Janković (1988) investigated and defined the latent structure of the technical-tactical elements in volleyball, on a sample of the four best volleyball teams that participated in the final tournament of the League Cup in former Yugoslavia 1981. Based on basic technical-tactical elements in volleyball, the author used a principal components analysis and extracted the following four latent dimensions: overall game efficacy, raising efficacy, efficacy of the backcourt play and efficacy after fast break. Trninić, Viskić-Štalec, Štalec, Dizdar, and Birkić (1995) conducted a quantitative analysis of the basketball game using multivariate mathematical-statistical methods (principal components analysis). The analysis was made taking into account the general and specific attributes of the game and tasks of the players in the game, based on the evaluation of top basketball experts (players and coaches) and knowledge of scientists-practitioners. Factor solutions have shown that there are three dimensions of a basketball game, the three components: information, energy and socio-motor interactions. The correlation between information and socio-motor interaction component was .38 , whereas the correlation between energy and socio-motor interaction component was negative. Trninić et al (2005) have attempted to determine the latent structure of a basketball game with alpha factor analysis, using 13 standard situational efficacy indicators in the basketball game, from the games of the World Basketball Championships held in Toronto in 1994, and they found four relatively independent latent dimensions: 1 . efficacy of the internal players or players in the back line of defense and attack in the front lines, 2. efficacy of external players or players in front of line of defense and back line of attack, 3. overall efficacy of the attack; 4. efficacy of throwing the ball into the basket from a distance. Thomson 
(1994) differentiates internal players and post-technique (facing back the basket), while Wissel (1994) describes the external players and specificity of the technique facing the basket. On the other hand, Javier (1992) divides players into two broad categories according to their roles in the game: external (organizer, producer and forward) and internal (post and pivot) players. Exploratory strategy of factor analysis of the main components of 13 standard indicators of situational efficacy on a sample of top junior basketball players who have participated in junior basketball championship in Zadar in 2000, there have been isolated two relatively independent latent dimensions and named as: technical and tactical situational activity (1) internal and (2) external players (Jeličić, Trninić, \& Jelaska, 2010). The authors conclude that neither the use of standard indicators of situational efficacy as well as the use of latent dimensions derived from them is not sufficient to explain the complex structure of the basketball game. The aim of the research conducted by Šeparović and Nuhanović (2008) was to determine the latent structure in basketball using factor analysis (alpha method, oblimin criteria of transformation) on 15 standard indicators of situational success (FI$\mathrm{BA}$ ), on the sample of 30 games in League six of Bosnia and Herzegovina, played for the championship of the state. Analyzing the structure of situational indicators that affect the success of the strongest basketball teams in Bosnia and Herzegovina state champion in basketball, it was shown that there are four latent dimensions, which are named: the success of a shot from close range, the success of the shot from moderate distance, the general success of defensive players and specific defensive mobility. However, the authors believe that for a complete analysis of latent structures it is necessary to expand the base of situational indicators.

The aim of the study was to determine the structure of the dimensions that can be found in the base of different standard parameters of situational efficacy in Croatian top basketball players. The discovery of the structure and relations of the latent dimensions of situational efficacy in basketball could contribute to better understanding of the overall situational efficacy of Croatian top basketball players. On the other hand, it could contribute to quality work of coaches and the training process could be organized in a more systematic way, in terms of differentiated action on important latent dimensions in the base of overall situational efficacy of the basketball players.

\section{METHODS}

\section{Participants}

The population from which the intentional sample of participants were drawn top players, who played in nine men's team A-1 Croatian men's basketball championship in 2006/2007: "Cedevita", "Svjetlost", "Borik", "Kvarner", "Dubrava", "Dubrovnik", "Alkar", "Šibenik", and "Osijek". The final sample of participants (74 players) is selected from an initial sample of 107 participants. The requirement for the selection of players in the final sample of participants was the number of minutes spent in the game (at least ten minutes in the game per match), or the number of matches played (at least eight matches in which the individual performed). Team players are examined with the permission of Croatian Basketball Federation, clubs and the players themselves, within a period of playing from the sixth to eighth round of the A-1 League championship (since December 2006 to mid-January 2007).

\section{Variables}

Criterias for the quantitative evaluation of the players were taken from the previously referenced papers in Croatia (Dizdar, 2002). In this paper we used the method of partial pondered linear combinations to evaluate the overall quality of basketball players (Ibid). There are thirteen standard parameters of situational efficacy, which include data on the shots success, rebounds, steals and turnovers, assists, blocks, personal fouls. On the basis of standard parameters of situational efficacy, is has been deduced seven derived coefficients of the situational efficacy of the basketball players: utilization of two points shots, utilization of for three-point shoots, utilization of free throw efficacy, efficacy of two-point shots, efficacy of three-point shoots, efficacy of free throws and efficacy of overall situational efficacy (Ibid). Data on the number of blocks of a shot in this study was omitted as it occurs rarely and we have no data about that. Derived parameters of situational effectiveness: efficiency coefficient of the two points shot: XK2IS XP2 $=/(\mathrm{XP} 2+\mathrm{XN} 2)$ Coefficient of efficiency for the three points shot: XK3IS XP3 $=/(+$ XP3 XN3) Coefficient of efficiency of free throws: XK1IS XP1 = / (XP1 + XN1); Coefficient of efficiency of the two points shot: XK2UC $=2 \mathrm{x} \times \mathrm{XK} 2 \mathrm{IS}$ $\mathrm{XP} 2$, Coefficient of efficiency for the three-point shot: XK3UC $=\times 3 \times$ XP3 XK3IS; Coefficient of efficiency of free throws: XK1UC $\mathrm{x}=\mathrm{XP1}$ XK1IS; Overall situational efficiency: XDLK $=\mathrm{XP1}+2 \mathrm{x}+$ 
$3 \times \mathrm{XP} 2 \mathrm{XP} 3+\mathrm{XSO}+\mathrm{XSN}+\mathrm{XA}+\mathrm{XOL}-0.5 \mathrm{XN} 1$

- XN2 - XN3 - XIL - XOP. We analyzed all the championship matches (using official statistics from the Croatian Basketball Federation website www.kosarka. $\mathrm{hr})$,.ie. sixteen matches for each of the nine teams in the "bicircular" system of competition.

\section{Statistical analysis}

To determine the structure of the dimensions that are basically a set of standard parameters of situational efficacy in basketball, it has been carried the procedure of Principal Components Analysis, where a number of significant principal components is determined by Guttman-Kaiser's criteria, while Varimax rotation has been applied afterwards. For a detailed analysis of the relationships of individual variables within the set of variables, there have been also determined intercorrelations (Pearson) between all the variables of the parameters set of the situational efficacy of basketball players.

\section{RESULTS}

In the Table 1, descriptive statistics of all situation-related parameters of efficacy at male basketball players in senior A-1 Croatian Basketball league was given.

In Table 2 is evident that it has been found even 48 (from the theoretically possible 72) statistically significant correlations, mostly medium-sized. The complementary variables highly and significantly correlate with each other: the number of successful and unsuccessful two-point shots, the number of successful and unsuccessful three-point shots, the number of successful and unsuccessful free throw. The smallest number of significant correlations with the others is found in the number of successful and unsuccessful three-point shots. Except for the high and significant correlation between the mutually complementary variables, there are successful and unsuccessful shots for two, three and one point for each standard parameterthere have been found at 9 or 10 significant correlations with the others. It is therefore realistic to conclude that the standard indicators of situational efficacy show, on average, the relatively high mutual connectivity.

Table 3 gives an overview of intercorrelation matrix for the set of variables from derived parameters of situational efficacy for a sample of senior basketball player from Team A-1 Croatian men's basketball league. There have been found 10 (of theoretically possible 28) statistically significant positive correlations that variate at values from low to very high. The largest number of statistically significant correlations (4) was found between overall situational efficacy (XDLK) and: the utilization of two -point shot, the efficacy of two-point shot, the efficacy of three-point shot, XK1UC i.e. efficacy of one -point shot. Also, four significant positive correlations were found between the efficacy of three-point shot, and: overall situational efficacy, efficacy of one-point shot, efficacy of three-point shot and utilization of one-point shot. Three significant correlations were found for XK1UC, i.e. efficacy of one-point shot and efficacy of two-point shot, the overall situational efficacy and efficacy of three-point shot. Also, there are three significant correlations found between XK2UC therefore efficacy of two-point shot, and utilization of two-point shot, efficacy of one-point shot and overall situational efficacy. Significant positive correlations were found between the derived parameters related to the two-point shot, i.e., the efficacy coefficient of two-point shots) and the utilization coefficient of two-point shot. Significant correlation was also found between efficacy of three point shot and the efficacy coefficient of three - point shot. Between efficacy coefficient of free throws and utilization coefficient of free throws, the correlation is not statistically significant.

In Table 4 the method of principal components analysis showed the existence of three latent dimensions, which together account for over $76 \%$ of the variance of the variables of standard situational efficacy parameters (whose characteristic roots are statistically significant according to the Kaiser-Guttman criteria, i.e., larger than 1). After varimax rotation, the first extracted component explains almost $29 \%$ of explained variance, and it is in the highest correlations with variables in the defensive and offensive reboun$\mathrm{ds}$ in the phase of attack (XSO and XSN), and successful and unsuccessful two-point shots (XP2 and $\mathrm{XN} 2$ ).

It is the most frequent standard parameters of situational efficacy, which usually serves as a "predominance" of the final result of the game. The second extracted component explains $17 \%$ of the overall variance, and the highest correlations with variables with successful and unsuccessful three-point shots (XP3 and XN3). Thus, it is a relatively rare but often decisive event for the outcome of the basketball game (three-point shot). The third extracted component explains $30 \%$ of the variance, and it is in the highest correlation with the variables of the remaining standard parameters of situational efficacy of the 
players (except for parameters that are in high correlations with the first and the second factor). One can roughly say that these are essentially "medium frequent" events at a basketball game. The highest values of communalities obtained for the variables: the number of successful two-point shots, i.e. XP2 and the number of turnovers, i.e. XIL (.83). They can explain most of the variance. It is possible that the highest communality values obtained for relatively frequent events at a basketball game, which are equally present for players at all positions in the team. The lowest communality values were obtained for the variables: the number of unsuccessful free throws, i.e. XN1, number of steals, i.e. XOP (.64), and the number of assists, i.e. XA (.66), which are probably characteristic only for the individual players' positions, i.e., defenders and playmakers.

\section{DISCUSSION}

Component analysis results show that in the space of standard parameters of situational efficacy we can single out three factors. The first factor is mostly saturated at a basketball game by the most frequent

TABLE 1

Descriptive statistics of all situation-related parameters of efficacy at male basketball players in senior A-1 Croatian Basketball league.

\begin{tabular}{lrrrrrrrrrr}
\hline Variable & $M$ & \multicolumn{1}{c}{ Min } & \multicolumn{1}{c}{ Max } & \multicolumn{1}{c}{$R$} & \multicolumn{1}{c}{ Var } & $S D$ & Skew & Kurt & Max D & $p$ \\
\hline XP2 & 34.03 & 2.00 & 115.00 & 113.00 & 515.53 & 22.71 & 1.07 & 1.14 & .12 & .20 \\
\hline XN2 & 26.99 & 4.00 & 79.00 & 75.00 & 246.81 & 15.71 & .93 & .92 & .08 & .20 \\
\hline XP3 & 12.00 & .00 & 39.00 & 39.00 & 85.18 & 9.23 & .74 & .07 & .11 & .20 \\
\hline XN3 & 23.12 & .00 & 61.00 & 61.00 & 272.90 & 16.52 & .51 & -.56 & .12 & .20 \\
\hline XP1 & 24.12 & 1.00 & 72.00 & 71.00 & 262.16 & 16.19 & .94 & .51 & .14 & .15 \\
\hline XN1 & 10.22 & .00 & 97.00 & 97.00 & 153.35 & 12.38 & 4.90 & 33.01 & .21 & .01 \\
\hline XA & 22.51 & 1.00 & 105.00 & 104.00 & 371.18 & 19.27 & 2.23 & 6.13 & .18 & .05 \\
\hline XSN & 13.88 & 1.00 & 48.00 & 47.00 & 114.11 & 10.68 & 1.28 & 1.32 & .17 & .05 \\
\hline XSO & 31.20 & 2.00 & 87.00 & 85.00 & 376.22 & 19.40 & .84 & .35 & .09 & .05 \\
\hline XOL & 14.45 & .00 & 34.00 & 34.00 & 60.41 & 7.77 & .24 & -.60 & .07 & .20 \\
\hline XOP & 33.23 & 4.00 & 64.00 & 60.00 & 146.40 & 12.10 & .08 & -.49 & .09 & .20 \\
\hline XIL & 21.39 & 3.00 & 55.00 & 52.00 & 134.41 & 11.59 & -.69 & -.31 & .13 & .20 \\
\hline XK2IS & .54 & .17 & .72 & .55 & .01 & .10 & -.72 & 1.05 & .08 & .15 \\
\hline XK3IS & .31 & .00 & .70 & .70 & .02 & .15 & -.39 & .68 & .16 & .20 \\
\hline XK1IS & .73 & .40 & 1.00 & .60 & .02 & .13 & -.12 & -.29 & .07 & .10 \\
\hline XK2UC & 38.88 & .67 & 147.77 & 147.10 & 855.97 & 29.26 & .74 & .14 & .14 & .20 \\
\hline XK3UC & 8.84 & .00 & 34.97 & 34.97 & 58.89 & 7.67 & .51 & -.44 & .13 & .15 \\
\hline XK1UC & 17.52 & .50 & 55.74 & 55.24 & 146.79 & 12.12 & 1.99 & 7.35 & .14 & .20 \\
\hline XDLK & 100.51 & -1.41 & 287.68 & 289.09 & 4217.37 & 64.94 & .72 & .34 & .08 & .20 \\
\hline
\end{tabular}

Legend: M - Mena; Min - Minimum; Max - Maximum; R - Range; Var - Variance;

SD - Standard deviation; Skew - Skewness; Kurt - Kurtosis; p - Probability;

XP2 - Number of successful two-point shots; XN2 - Number of unsuccessful two-point shots; XP3 - Number of successful three-point shots; XN3 - Number of unsuccessful three-point shots; XP1 - Number of successful free throws; XN1 - Number of unsuccessful free throws; XA - Number of assists; XSN - Number of offensive rebounds; XSO - Number of defense rebounds; XOP - Number of personal fouls; XIL - Turnovers; XK2IS - Utilization coefficient for two-points shot XK3IS - Utilization coefficient for three-points shot; XK1IS - Utilization coefficient of free throws; XK2UC - Utilization coefficient for two-points shot; XK3UC - Utilization coefficient for three-points shot; XK1UC - Utilization coefficient for free throws; XDLK - Overall situational efficacy. 
TABLE 2

Intercorrelations between the standard situation-related parameters of efficiency at male basketball players in senior A-1 Croatian Basketball league.

\begin{tabular}{|c|c|c|c|c|c|c|c|c|c|c|c|}
\hline Variables & XP2 & $\mathrm{XN} 2$ & XP3 & $\mathrm{XN3}$ & XP1 & $\mathrm{XN1}$ & $\mathrm{XA}$ & XSN & $\mathrm{XSO}$ & XOL XOP & XIL \\
\hline XP2 & 1.000 & & & & & & & & & & \\
\hline $\mathrm{XN} 2$ & .825 & 1.000 & & & & & & & & & \\
\hline XP3 & .004 & .066 & 1.000 & & & & & & & & \\
\hline $\mathrm{XN3}$ & .041 & .134 & .838 & 1.000 & & & & & & & \\
\hline XP1 & .645 & .635 & .292 & .328 & 1.000 & & & & & & \\
\hline $\mathrm{XN1}$ & .504 & .477 & -.118 & .081 & .618 & 1.000 & & & & & \\
\hline $\mathrm{XA}$ & .269 & .322 & .206 & .165 & .399 & .288 & 1.000 & & & & \\
\hline $\mathrm{XSN}$ & .717 & .543 & -.133 & -.089 & .421 & .268 & -.037 & 1.000 & & & \\
\hline $\mathrm{XSO}$ & .714 & .607 & .030 & .127 & .485 & .381 & .117 & .759 & 1.000 & & \\
\hline $\mathrm{XOL}$ & .488 & .568 & .378 & .369 & .592 & .386 & .562 & .201 & .415 & 1.000 & \\
\hline $\mathrm{XOP}$ & .457 & .546 & .147 & .212 & .591 & .368 & .464 & .429 & .477 & $\begin{array}{ll}.656 & 1.000 \\
\end{array}$ & \\
\hline XIL & .677 & .678 & .193 & .300 & .735 & .533 & .679 & .363 & .476 & $.637 \quad .630$ & 1.000 \\
\hline
\end{tabular}

Legend: XP2 - Number of successful two-point shots; XN2 - Number of unsuccessful two-point shots; XP3 - Number of successful three-point shots; XN3 - Number of unsuccessful three-point shots; XP1 - Number of successful free throws; XN1 - Number of unsuccessful free throws; XA - Number of assists; XSN - Number of offensive rebounds; XSO - Number of defense rebounds; XOL - Steals; XOP - Number of personal fouls; XIL - Turnovers.

\section{TABLE 3}

Intercorrelations between the derived situation-related parameters

of efficiency at male basketball players in senior A-1 Croatian Basketball league.

\begin{tabular}{l|rrrrrrr}
\hline Variables & XK2IS & XK3IS & XK1IS & XK2US & XK3US & XK1US & XDLK \\
\hline XK2IS & 1.000 & & & & & & \\
\hline XK3IS & .055 & 1.000 & & & & & \\
\hline XK1IS & -.113 & .244 & 1.000 & & & & \\
\hline XK2UC & .568 & -.047 & -.169 & 1.000 & & & \\
\hline XK3UC & .065 & .613 & .349 & -.022 & 1.000 & & \\
\hline XK1UC & .172 & .187 & .170 & $\mathbf{. 5 3 0}$ & $\mathbf{. 3 7 0}$ & 1.000 & \\
\hline XDLK & .484 & .196 & -.017 & $\mathbf{. 8 7 1}$ & $\mathbf{. 3 4 0}$ & $\mathbf{. 6 8 3}$ & 1.000 \\
\hline
\end{tabular}

Legend: XK2IS - Utilization coefficient for two-points shot; XK3IS - Utilization coefficient for three-points shot; XK1IS - Utilization coefficient of free throws; XK2UC - Utilization coefficient for two-points shot; XK3UC - Utilization coefficient for three-points shot; XK1UC - Utilization coefficient for free throws; XDLK - Overall situational efficacy.

standard parameters of situational efficacy, which usually bring in basketball the "predominance" of the results of the game (rebounds in the phase of offense and defense and successful and unsuccessful two - point shots). Another factor in the area of standard parameters describes relatively rare but often decisive events for the outcome of the match at a basketball game (successful and unsuccessful three - point shots). The third factor in the area of standard parameters describes "medium frequent" events at a basketball game: assists, free throws, steals and turnovers. The relative contribution of these factors explains the importance of certain parameters of situational effi- 


\section{TABLE 4}

Principal components analysis with V arimax rotation (standard situation-related parameters

of efficiency at male basketball players in senior A-1 Croatian Basketball league).

\begin{tabular}{|c|c|c|c|c|}
\hline \multirow{2}{*}{ Variables } & \multicolumn{3}{|c|}{ Factor } & \multirow{2}{*}{$R^{2}$} \\
\hline & 1 & 2 & 3 & \\
\hline XP2 & .810 & -.034 & .431 & .840 \\
\hline $\mathrm{XN} 2$ & .679 & .045 & .526 & .737 \\
\hline XP3 & -.057 & .955 & .101 & .820 \\
\hline $\mathrm{XN3}$ & .027 & .927 & .146 & .797 \\
\hline XP1 & .497 & .253 & .640 & .744 \\
\hline $\mathrm{XN1}$ & .346 & -.161 & .587 & .594 \\
\hline $\mathrm{XA}$ & -.155 & .077 & .869 & .657 \\
\hline $\mathrm{XSN}$ & .915 & -.105 & .021 & .747 \\
\hline $\mathrm{XSO}$ & .866 & .084 & .180 & .687 \\
\hline $\mathrm{XOL}$ & .256 & .355 & .720 & .669 \\
\hline XOP & .407 & .165 & .619 & .637 \\
\hline XIL & .379 & .149 & .820 & .827 \\
\hline CR & 3.473 & 2.064 & 3.611 & \\
\hline$\% \mathrm{EV}$ & 28.940 & 17.198 & 30.088 & \\
\hline
\end{tabular}

Legend: XP2 - Number of successful two-point shots; XN2 - Number of unsuccessful two-point shots; XP3 - Number of successful three-point shots; XN3 - Number of unsuccessful three-point shots; XP1 - Number of successful free throws; XN1 - Number of unsuccessful free throws; XA - Number of assists; XSN - Number of offensive rebounds; XSO - Number of defense rebounds; XOL - Steals; XOP - Number of personal fouls; XIL - Turnovers; $\mathbf{R}^{2}$ - Square of multiple correlation; CR - Characteristic root; $\% \mathbf{E V}$ - $\%$ of explained variance.

cacy for the interpretation of the entire area of situational efficacy of basketball players. The most common (first factor) and medium common (third factor) in the area of situational efficacy parameters (together make almost $60 \%$ of overall variability). The three-point shots stand out as an isolated entity, which in relative relationship (defined using only two variables) provides a significant contribution to the interpretation of situational efficacy area. There is a certain similarity between the results obtained in the research of Trninić et al (1995), since the dimensions of the efficacy of internal players or players in the back line of defense and the front line of offense corresponds to a certain extent in our study to the first factor, while our second factor is more like a dimension of the efficacy of throwing a ball into the basket from a distance. There is a similarity with latent dimensions that have received Jeličić et al. (2010): the first factor corresponds primarily to the situational technical and tactical activities of the internal players, and the second factor and third factor of the external players activities. There is a certain correspondence with research of Šeparović and Nuhanović (2008), where latent structure obtained in our study shows a certain correspondence between the success of a shot from close range and our first factor, the success of a shot from the middle distance and other factors, the general success of the defensive players and defensive specific mobility and our third factor. At the level of analysis of the individual relationship between variables, standard parameters of situational efficacy in this study indicate, on average, relatively high positive, mutual correlation. And in this way it can be shown that the standard parameters of situational efficacy describe coherent "general" situational efficacy of basketball players in a series of basketball games. Thus, the derived parameter of overall situational efficacy represents a justified measure of the area of the situational efficacy of the players. Mutually complementary variables showed the strongest connections, which means that the most successful basketball players, shooting for two or three points or one point, also have the most unsuccessful shots. This may be another indication of the justification 
of the interpretation that the basketball players differ not only in terms of overall time spent in the game (as a member of the first team or reserve players), but also in terms of the position and role in the team that determines their shapes (parameters) of situational efficiacy (point guard, shooting guard, small forward, center, power forward). The smallest number of significant correlations with other variables of situational efficacy parameters was found in successful and unsuccessful three point shots, which further confirms the results of the factor analysis, i.e. isolated factor that describes three-point shot. It is likely that the three-point shots represent a technical element which depends on the specific training, and it is used selectively during a basketball game. On the other hand, they are relatively rare in the basketball game. To discuss intercorrelations of derived parameters of situational efficacy is only partly justified, because of the larger number of spurious correlations conditioned by the same standard parameters of situational efficacy in the formulas for calculating the derived parameters. The correlation between the efficacies of derived parameters is probably a logical consequence of the different concepts of logic of derived parameters, which contain virtually three different types of coefficients: efficacy of shots, utilization of shots, and overall situational efficacy. Coefficients of two, three and one point shot efficacy are more significantly associated than utilizations coefficients of shots. The utilization coefficients of shots are better linked with overall situational efficacy of basketball players. One reason for this is certainly the fact that the correlations between overall situational efficacy and coefficient of shots efficacy spurios, because they are result of defining the formula of calculating mentioned coefficient. Overall situational efficacy is derived from the coefficients of shots efficacy, not from shots utilization coefficient. Coefficients of shots efficacy (and overall situational efficacy) include not only the percentage of successful shots (i.e. the proportion of the number of successful shots in relation to the total number of shots), but the number of successful shots. However, a better interconnection of efficacy coefficients compared to the utilization coefficients can indicate a greater possibility that the efficacy coefficients better describe what has been called "better quality" (overall situational efficacy) of the players. Specifically, situationally more effective or "quality" basketball player is one that is not only optimally effective in a relatively narrow domain of given tasks, either by the coach or what the position he plays in the team requires. Quality basketball player is willing to take responsibility for the team as a whole, for example in terms of shooting at the basket in the situation when the co-player who is primarily responsible fot that task is being well-guarded by the opponent player. Therefore, it is likely that efficacy coefficients reflect better the real (rather than only mathematical) overall situational efficacy of basketball player who, regardless of his position in the team, is "good enough" in all kinds of shots, and decides more often to shot than the average basketball player the team (Sindik, 2009).

The main advantage of this study was the fact that all available basketball players in the studied championship of A-2 basketball league were tested. From there, there have been discovered laws that may be applied to the specific sample (virtually the population) of basketball players, which can be an incentive for quality coach work. However, to the smaller the possibility of generalization of the results there are several reasons that may affect: lower and multiply selected sample of participants, the specificity of the Croatian population of top senior basketball players, the specificity of a particular event (in the investigated championship, there were no teams that could fall out of the league, which could affect competitiveness of teams fought for survival in the A-1 league). In future research we could try to slightly increase number of participants (try to examine the injured and for other reasons absent players), which can be achieved only minimally. The term "top basketball players" in relation to the abovementioned specifics really varies considerably from country to country, depending on the quality of the competition in the specific state (which often depends on the financial resources of clubs to hold to their own perspective players). On the quality of the basketball competitions in our country generally it cannot be significantly affected, except for long-term, systemic change of competitions and financial possibilities of the teams. Consequently, one of the solutions for the future research is multiple replication of equivalent research over a number of basketball championships, where these small differences in the concept of Croatian "top basketball players" may be reflected. For long-term increase of competitive uncertainty (i.e. tie of the teams competing in the championship), maybe we could implement solutions similar to the one in the American NBA league. A kind of "draft"-list, where less successful teams resulting could have an advantage in the selection of quality young players, could equalize the competitive quality of the team. At the level of practical implications, based on the latent structure data it would be possible to divide the situational basketball training into three parts: situational training of rebounds combined with a two-point shots 
(1); situational training of three-point shots (2), situational training of other parameters of situational efficacy, assists, free throws, steals and decrease the number of turnovers and personal fauls (3).

\section{CONCLUSIONS}

Distribution of situational efficacy parameters, on average, followes a "normal" distribution of events at basketball games and basketball competitions in general, and they are significantly mutually associated. There are three fundamental latent dimensions that explain the area of situational efficacy of basketball players. The dimensions can differ from each other by the frequency of representation of events at the basketball game.

\section{REFERENCES}

Abrams, W., Barnes, J. C., \& Clement, A. (2008). Relationship of selected pre-NBA career variables to NBA players' career longevity. The sport journal, 11(2). Retrived from http://www. thesportjournal.org/article/relationshipselected-pre-nba-career-variables-nba-playerscareer-longevity.

Dežman, B. (1996). Dijagnosticiranje morfološkoga, motoričkoga i igračkoga statusa mladih košarkaša [Diagnosing morphological, motor and the playing status of the youth basketball players]. Kineziologija, 28(2), 42-45.

Dizdar, D. (2002). V rednovanje skupa metoda za procjenu stvarne kvalitete košarkaša [Evaluation expensive method to assess the actual quality of basketball]. Unpublished doctoral dissertation, University of Zagreb, Faculty of Kinesiology.

Elbel, E. R., \& Allen, F. (1941). Evaluating team and individual performance in basketball. Research quaterly, 12(3), 538-557.

Erčulj, F. (1997). Usporedba različitih kriterija učinkovitosti u košarci [Comparison of different efficiency criteria in Basketball]. Kineziologija, 29(1), 42-48.

Gréhaigne, J.-F., Bouthier, D., \& Godbout, P. (1997). Performance Assessment in team sports. Journal of Teaching in Physical Education, 16, 500516.

Hernandez, J. (1988). Baloncesto iniciacion y entrenamiento [Basketball initiation and training]. Barcelona, ES: Editorial Paidotribo.

Javier, O. (1992). 1250 ejercicios y juegos en baloncesto [1250 basketball drills and playes]. Barcelona, ES: Editorial Paidotribo.
Janković, V. (1988). Latentna struktura tehničko - taktičkih elemenata u odbojkaškoj igri [Latent structure of the technical - tactical elements in volleyball game]. Kineziologija, 20(1), 57-62.

Jeličić, M., Trninić, M., \& Jelaska, I. (2010). Latent structure of situational efficiency of elite junior basketball players. Sport Science, 3(1), 65-70.

Jukić, I. (1998). Praćenje motoričko-funkcionalne pripremljenosti u jednogodišnjem ciklusu treninga vrbunskih košarkašica [Monitoring motorfunctional preparation in the one-cycle training of top female basketball players]. Unpublished master thesis, University of Zagreb, Faculty of Physical Culture.

Milanović, D., Jukić, I., \& Bračić, M. (2001). Utjecaj varijabli ubacivanja lopte u koš na rezultate košarkaških utakmica Prvenstva Europe u Barceloni 1997. godine [Influence of variables basketball shooting on the game results of the European Championships in Barcelona 1997]. In D. Milanović (Ed.) Zbornik radova Kineziologija za 21. stoljeće (pp. 286-289). Opatija, HR: Fakultet za fizičku kulturu.

Milanović, D., Jukić, I., \& Dizdar, D. (1996). Dijagnostika funkcionalnih i motoričkih sposobnosti kao kriterij za selekciju košarkaša Diagnosis of functional and motor abilities as a criterion for the selection in basketball]. Kineziologija, 28(2), 42-45.

Nakić, J. (2004). Razllike u standardnim $i$ izvedenim parametrima situacijske učinkovitosti između muških $i$ ženskih košarkaških ekipa na seniorskim košarkaškim europskim prvenstvima 2003. godine [Differences in standard and derived parameters situational performance between male and female basketball teams in the senior European basketball championships 2003]. Unpublished master thesis, University of Zagreb, Faculty of Kinesiology.

Sindik, J. (2009). Povezanost konativnih obilješja vrbunskih košarkaša i situacijske ncinkovitosti u košarci [Correlation conative characteristics and situational performance of top level basketball players]. Unpublished doctoral dissertation, University of Zagreb, Faculty of Kinesiology.

Swalgin, K. (1994). The basketball evaluating system. A scientific approach to player evaluation. In J. Krausse (Ed.), Coaching basketball (pp. 40-43). Indianapolis, IN: Master Press.

Swalgin, K. (1998). Sustav ocjenjivanja u košarci [Evaluation system in basketball]. Kineziologija, 30(1), 30-36.

Šeparović, V., \& Nuhanović, A. (2008). Latent structure of standard indicators of situational 
effectiveness in basketball in Bosnian league 6. Sport Scientific and Practical Aspects, 5(1/2), 13-18. Thompson, J. (1994). Inside players. In J. Krause (Ed.), Coaching basketball (pp. 40-43). Indianapolis, IN: Master Press..

Trninić, S., \& Dizdar, D. (2000). System of the performance evaluation criteria weighted per positions in the basketball game. Collegium Antropologicum, 24(1), 217-234.

Trninić, S., Perica, A., \& Dizdar, D. (1999). Set of criteria for the actual quality evaluation of the elite basketball players. Collegium Antropologicum, 23(2), 707-721.
Trninić S., Perica, A., \& Dizdar, D. (2001). Criteria for the situation related efficiency evaluation of the elite basketball players. In D. Milanović (Ed.), Kineziologija za 21. stoljeće (pp. 236-239. Opatija, HR: Fakultet za fizičku kulturu.

Trninić, S., Viskić-Štalec, N., Štalec, J., Dizdar D., \& Birkić, Ž. (1995). Latentna struktura standardnih pokazatelja situacijske efikasnosti u košarkaškoj igri [Latent structure of the standard indicators of situational efficiency in basketball game]. Kineziologïa, 27(1), 27-37.

Wissel, H. (1994). Basketball: Step to success. Champaign, IL: Human Kinetics.

Received: September 6, 2012 Revision received: December 6, 2012

Accepted: December 6, 2012

Correspondence to: Joško Sindik, PhD Institute of Anthropology Gajeva 32 10000 Zagreb Croatia

Phone: 0038515535122 E-mail: josko.sindik@inantro.hr 